Automation and Robotics in Construction $X$

\title{
Simulation Analysis of Process Piping Construction
}

\author{
Min-Yuan Cheng and James T. O'Connor ${ }^{\mathbf{b}}$ \\ aDepartment of Construction Engineering \& Technology, National Taiwan Institute of \\ Technology, Associate Professor
}

bDepartment of Civil Engineering, University of Texas at Austin, Associate Professor

\begin{abstract}
Previous research has demonstrated that automation can improve industrial pipe lifting productivity. However, there is little information on finding how much productivity can be improved in the other parts of pipe erection processes to coordinate with the productivity improvement in pipe lifting. The processes of piping construction include pipe delivery, pipe lifting, pipe alignment, pipe connection, and pipe inspection \& connection. This paper studied the potential productivity improvement by simulating the process of piping operations in order to synchronize with the productivity improvement in piping lifting. This paper is based in part on previous findings from studies performed by Glass and Fisher at the University of Texas at Austin in 1984 and 1989. The semi-automated environment for piping erection assumes a Grove Pipe Manipulator attached to the boom nose of a 22-ton crane as the base piece of equipment for piping erection. A system model is established to simulate and analyze the process of piping construction. A simulation technique is developed in this study to identify the possible critical tasks and the factors of obstruction in the process of piping construction that would eliminate the productivity improvement in piping erection.
\end{abstract}

\section{BACKGROUND}

The Manipulator was first brought into construction in 1980. Since then the Pipe Manipulator has been modified several times for the problems of technical utilization and was tested in the construction industry for handling large scale of piping construction. The Pipe Manipulator is an electrohydraulically control, multifunction, large bore pipe handling device which consists of five major components, namely a side mounted gravity leveling operator's basket with control panel, an attaching support frame, a telescoping boom, a pipe grappling and pivot head assembly, and a free standing storage rack for the unit when it is not being used (Glass 1984). Glass developed his study in comparing the productivity of the Pipe Manipulator with conventional piping erection method using a small, 15-ton hydraulic "Cherry Picker"(Glass 1984). In the Glass' study, it was found that the Pipe Manipulator was superior to conventional piping erection when lifting large diameter, vertical and bent pipe configurations. Fisher, in 1989, summarized piping erection activities and the percentage of cycle breakdowns of time, from two of Glass' time lapse films, for horizontal piping erection (film D-3 and D-4). Fisher's findings, from the imitation of the paths in time lapse films D-3 and D-4 to record the process of simulation on plastic and computer models, indicated that the Pipe Manipulator could be improved through four phases of piping erection method. In each phase, constructability issues associated with piping construction was explored and improved to promote a more automated operation. 


\section{METHODOLOGY}

This study was conducted in three steps:

1. establish a cycle model to simulate the piping installation process,

2. identify the critical work tasks (i.e., bottleneck activities), and

3. study sensitivity analysis to determine the optimal combinations of labor crew (i.e.,
fitter and welder) under different circumstances.

\subsection{The Cycle Model}

This study used MicroCyclone developed by Professor Daniel Halpin in 1986 to simulate the process of piping construction. Twelve individual flow unit cycles were established in the model: (1) Pipe erection cycle, (2) Crane cycle, (3) Load pipe cycle, (4) Pipe transportation cycle, (5) Manipulator cycle, (6) Manipulator respoting cycle, (7) Fitter cycle, (8) Remove empty cart cycle, (9) Welder cycle, (10) Clear \& inspect cycle, (11) Reweld cycle, and (12) Clear and inspect \& reweld cycle. Figure 1 shows the integrated model.

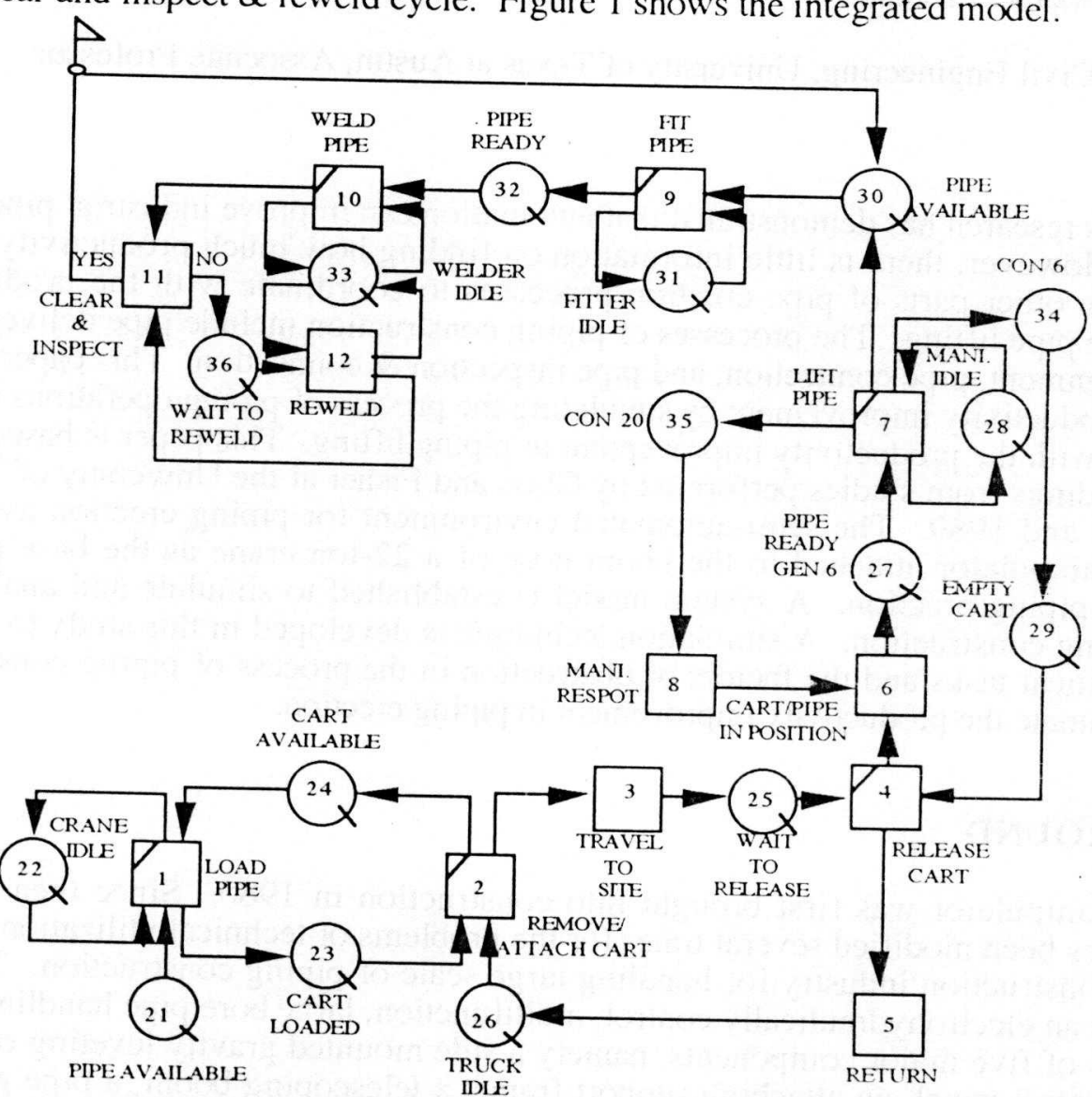

Figure 1 The final integrated model for piping process

\subsection{Identification of the Critical Work Tasks}

By simulating the developed cycle model, the critical work tasks of process piping construction were identified in this step. From the output reports of simulation, the critical work tasks could be identified by checking the percentage of work task that is busy and the pereentage of queue that is occupied. The percentage of work task that is busy is the percentage of time the work task was in operation. The percentage of queue that is occupied is the percentage of time that a unit was waiting (or "idle time") in the queue before moving to the following work task. The last term is a key indicator of the delays that occurred in the process. 


\subsection{Sensitivity Analysis}

This section discusses the objective statements and both the Tree Algorithm and the Time Deviation methods used for analyzing this study. Tree Algorithm method includes a tree combination of resources and comparison of different interest to approach the decision-making process. Time Deviation method analyzes the best range of time control of critical activity that could achieve maximum productivity increase.

\subsubsection{Objective Statement}

The purposes of this study is to establish a cycle model to simulate the piping installation process, identify the critical work tasks (i.e.., bottleneck activities), analyze the frequency of pipe delivery (\# of trucks), and determine the number of labor crew (i.e.., fitter and welder) under different circumstances. This study involves different effects, given different combinations of trucks, fitting crews, welding crews, and productivity rates between conventional and improved piping erection methods.

Three major objectives are concerned in this study:

Objective 1: Use standard and conventional piping erection process in the model to simulate and identify the possible critical work task. Analyze the combination of trucks, fitting crews and welding crews required in coordinating with pipe lifting activity. Different goals such as maximum productivity per hour (Spools/HR), maximum productivity per man-hour (Spools/MH), least idle time of pipe waiting the Manipulator to lift can be achieved with a Tree Algorithm method. Depending on the different interests, the decision-maker would like to trade-off according to the results to make his best decision.

Objective 2: Findings from D.J. Fisher "Piping Erection Constructability Issues In a Semi-Automated Environment" include specific suggestions that would improve the Pipe Manipulator performance by $48 \%$ over conventional piping erection methods. Four types of studies to improve Pipe Manipulator installation cycle time were identified in Fisher's study (see Table 1). Based on the improvement of cycle time in each phase, this paper identified the best combination of trucks and labor crews to coordinate with the productivity improvement of the Pipe Manipulator. Also, under each Manipulator cycle time, the sensitivity analysis (Tree Algorithm method) is used to analyze the goals as mentioned in objective 1.

Table 1 Total Cycle Time of Pipe Manipulator

\begin{tabular}{|c|c|c|c|c|}
\hline $\begin{array}{c}\text { ANALYSIS } \\
\text { METHOD }\end{array}$ & Time Lapse & $\begin{array}{l}\text { 1. computer } \\
\text { 2. Plastic }\end{array}$ & $\begin{array}{l}\text { 1. computer } \\
\text { 2. Plastic }\end{array}$ & $\begin{array}{l}\text { 1. computer } \\
\text { 2. Plastic }\end{array}$ \\
\hline Condition & Time Lapse & Time Lapse & Nominal & Optimal \\
\hline \hline Total Cycle Time & $\mathbf{1 1 1 6}(\mathbf{s e c})$ & $\mathbf{9 0 1 . 5}$ & $\mathbf{8 3 2 . 5}$ & $\mathbf{7 0 2}$ \\
\hline
\end{tabular}

Objective 3: Under a certain combination derived from objective 2, the model is simulated based on increasing or decreasing the percentage of the operation time of the critical work task. "FIT PIPE" and "WELD PIPE" were analyzed by increasing or decreasing the activity duration twenty percent each time. Calculating and comparing the slope of productivity on each increasing or decreasing phase, the modeler can tell the optimal phase (i.e., the phase with the maximum slope) of improving the duration of activity that may achieve the maximum productivity increment.

\subsubsection{Tree Algorithm Method}

Tree Algorithm is a method used in sensitivity analysis to determine optimal piping productivity (Spools/HR) by using different combinations of trucks, fitters, and welders (see Figure 2). The method is to test the effect of changing the number of trucks, fitters, and welders based on the behavior of the system. Different approaches such as maximum productivity per hour (Spools/HR), maximum productivity per man-hour (Spools/MH), and least idle time for waiting for the Manipulator to lift could be achieved with this method. 


\subsubsection{Time Deviation Method}

Time deviation is another method used in sensitivity analysis. Some of the work task time in the model are variables. One of the variables can be fixed and the work task time can be increased or decreased by a certain percentage (see Table 2). The results of the Time Deviation method can give us information about time control. The Time Deviation method is presented in a series of diagrams. These diagrams show the impact of productivity (vertical scale) as a function of the percentage of change of a variable (horizontal scale). The steeper the slope of the curve, the more sensitive is the range.

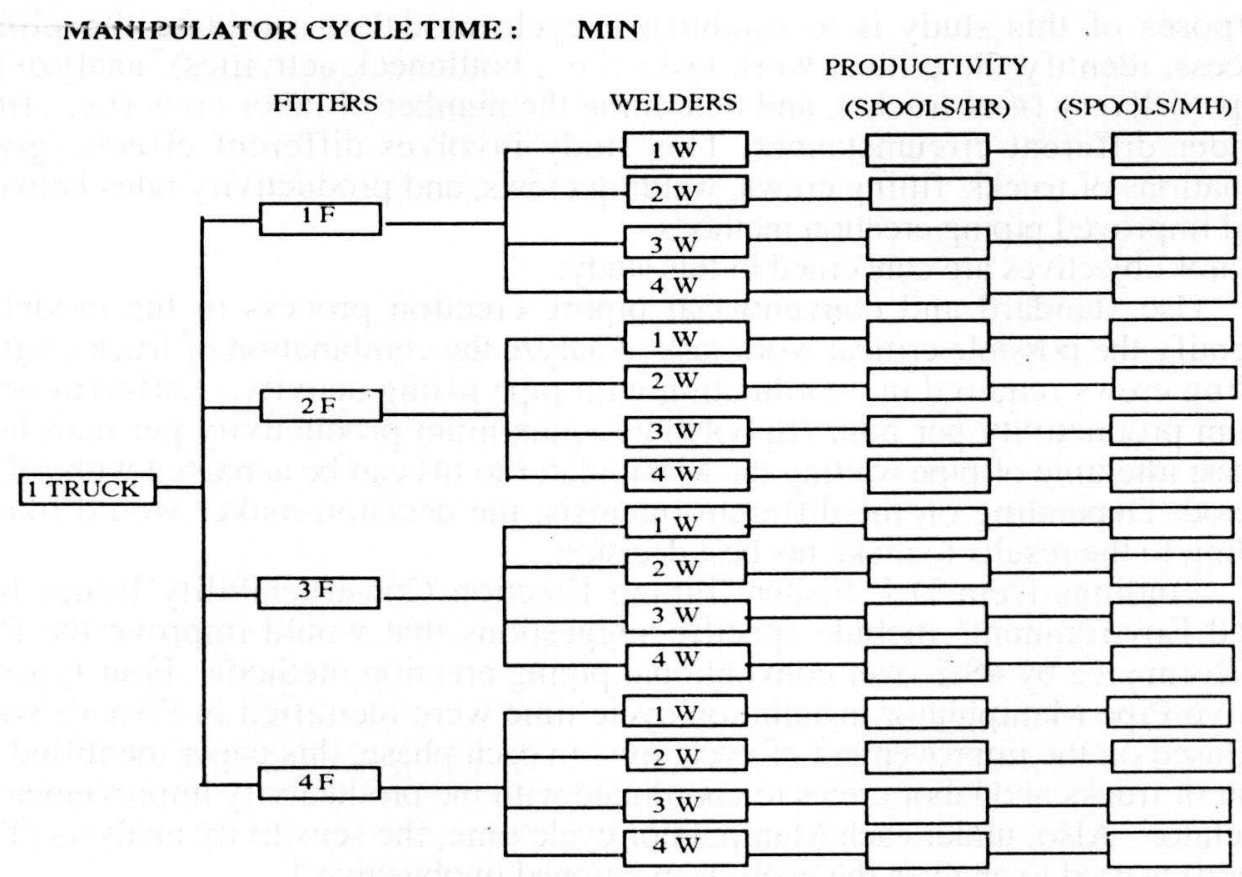

Table 2 Time Deviation Method

Figure 2 Tree Algorithm Method

MANIPULATOR DURATION $=\min$

FITTER 1 WELDER 1

DEVIATION

\begin{tabular}{|l|l|l|l|l|l|l|l|l|l|}
\cline { 2 - 9 } \multicolumn{1}{l|}{ WORK TASKS } & $-60 \%$ & $-50 \%$ & $-40 \%$ & $-30 \%$ & $-20 \%$ & $-10 \%$ & 0 & $20 \%$ & $40 \%$ \\
\hline FTT PIPE & & & & & & & & & \\
\hline WELD PIPE & & & & & & & & & \\
\hline
\end{tabular}

FITTER 2 WELDER 2

DEVIATION

\begin{tabular}{|l|l|l|l|l|l|l|l|l|l|}
\cline { 2 - 9 } \multicolumn{1}{l|}{ WORK TASKS } & $-60 \%$ & $-50 \%$ & $-40 \%$ & $-30 \%$ & $-20 \%$ & $-10 \%$ & & $20 \%$ & $40 \%$ \\
\hline FTT PIPE & & & & & & & & & \\
\hline WELD PIPE & & & & & & & & & \\
\hline
\end{tabular}

FITTER 2 WELDER 3

DEVIATION

\begin{tabular}{|c|c|c|c|c|c|c|c|c|c|}
\hline WORK TASKS & $-60 \%$ & $-50 \%$ & $-40 \%$ & $-30 \%$ & $-20 \%$ & $-10 \%$ & 0 & $20 \%$ & $40 \%$ \\
\hline FIT PIPE & & & & & & & & & \\
\hline WELD PIPE & & & & & & & & & \\
\hline
\end{tabular}

FITTER 3 WELDER 4

\begin{tabular}{|l|l|l|l|l|l|l|l|l|l|}
\cline { 2 - 9 } WORK TASKS & $-60 \%$ & $-50 \%$ & $-40 \%$ & $-30 \%$ & $-20 \%$ & $-10 \%$ & 0 & $20 \%$ & $40 \%$ \\
\hline FIT PIPE & & & & & & & & & \\
\hline WELD PIPE & & & & & & & & & \\
\hline
\end{tabular}




\section{DATA ANALYSIS AND RESULTS}

\subsection{Description of simulation}

The results of simulation were obtained under the assumption that as the limited working space, the maximum number of fitter and welder assigned one Manipulator is no more than four. Under different Manipulator erection cycle time, simulation with 1 truck 1 fitter \& 1 welder, 1 truck 1 fitter \& 2 welders, 1 truck 1 fitter \& 3 welders etc. (also 1 truck 2 fitters \& 1 welder, 1 truck 2 fitters \& 2 welders etc.) is run and the results in terms of productivity per hour, and per man-hour are identified. Referring to Table 1 (different total cycle time of Manipulator), the Tree-Algorithm method were applied to simulate the model. Taking all possible combinations of resources for the work task "LIFT PIPE" and within the limits specified, the program finished simulating 16 different possible combinations under 8 different erection cycle times for the Manipulator. Tables 3 and 4 show the simulation results of five different combinations (1F1W, 1 F2W, 2F2W, 2F3W,3F4W).

Table 3 Results of simulation: The productivity per hour VARIABLE : MANIPULATOR CYCLE TIME MANI. CYCLE TIME (MIN)

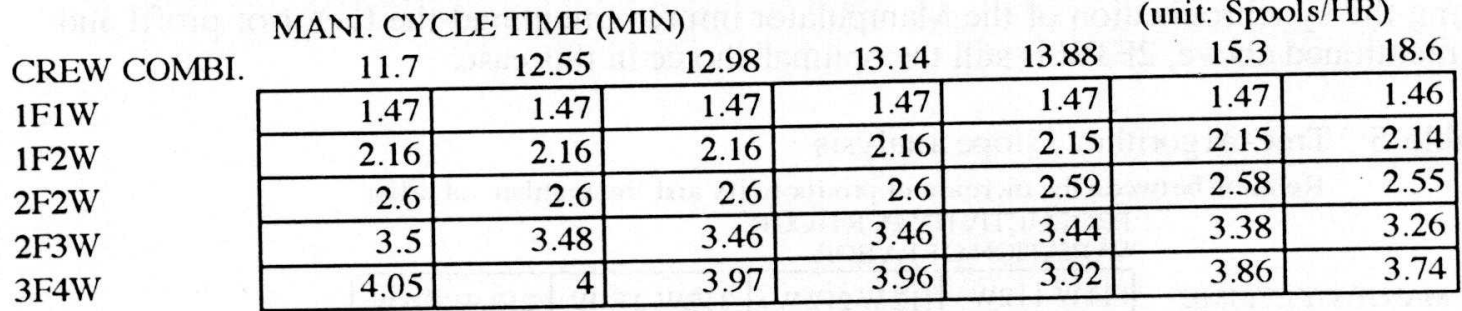

Table 4 Results of simulation: The productivity per man-hour (Spools/MH) VARIABLE : MANIPULATOR CYCLE TIME MANI. CYCLE TIME (MIN)

\begin{tabular}{l|r|r|r|r|r|r|r|}
\multicolumn{2}{c}{ MAN. CYCLE } \\
CREW COMBI. & \multicolumn{1}{c}{11.7} & 12.55 & 12.98 & 13.14 & 13.88 & 15.3 & 18.6 \\
\cline { 2 - 8 } 1F1W & 0.735 & 0.735 & 0.735 & 0.735 & 0.735 & 0.735 & 0.73 \\
\cline { 2 - 8 } 1F2W & 0.72 & 0.72 & 0.72 & 0.72 & 0.717 & 0.717 & 0.713 \\
\hline 2F2W & 0.65 & 0.65 & 0.65 & 0.65 & 0.648 & 0.645 & 0.638 \\
\cline { 2 - 8 } 2F3W & 0.7 & 0.696 & 0.692 & 0.692 & 0.688 & 0.676 & 0.652 \\
\hline 3F4W & 0.579 & 0.571 & 0.567 & 0.566 & 0.56 & 0.551 & 0.534 \\
\cline { 2 - 8 }
\end{tabular}

As stated in objective statements, the purpose of this study is to find the optimal combination to coordinate with the productivity improvement in pipe lifting. Therefore the first thing that needs to be improved is the capability of $1 F 1 \mathrm{~W}$ which is not enough to handle the productivity improvement in pipe lifting. Referring to Table 3 , the modeler notices that the productivity of $1 \mathrm{~F} 1 \mathrm{~W}$ didn't increase simultaneously as the Manipulator cycle time decreased. Bottleneck activity "FIT PIPE" eliminated the productivity improvement of the Manipulator by increasing the waiting time in QUEUE node 30 "PIPE AVAILABLE" which precedes it. The waiting time of pipe to be welded at QUEUE 32 was also increasing as the Manipulator cycle time decreased. For $1 \mathrm{~F} 2 \mathrm{~W}$, the increment of productivity stagnated at $2.16 \mathrm{Spools} / \mathrm{HR}$ and did not increase as the Manipulator cycle time decreased. The same situation took place in the case of $2 \mathrm{~F} 2 \mathrm{~W}$ (see Table 3 ). If the modeler wants to increase productivity and bring the Manipulator into full play, he has to add more resources into the process in order to synchronize it with the productivity improvement of the Manipulator.

\subsection{Tree-Algorithm Analysis}

Case of maximum productivity per hour

Reading through all of the results in the Table 3 which were simulated under different conditions, 3F4W is always the optimal combination to achieve the maximum productivity per 
hour. The results of simulation conclude that the more the productivity of the Manipulator is improved, the more the productivity of labor (including the number of laborers and motivation factors) needs to be improved.

With regards to cost, another approach was studied to find the best combination. Table 5 shows the productivity slope analysis derived from Table 3 . The table was obtained by fixing the cycle time of the Manipulator (the vertical column) and calculating the slope of the productivity between different combinations of working crews (the horizontal row). In the table, the value of productivity increase in the third column is always the largest in comparison with the value in the other columns. Therefore the maximum increase in the rate of productivity can be obtained for additional labor from $2 \mathrm{~F} 2 \mathrm{~W}$ to $2 \mathrm{~F} 3 \mathrm{~W}$. Considering the factor of profit and cost, $2 \mathrm{~F} 3 \mathrm{~W}$ will become the optimal choice.

Case of maximum productivity per man-hour

In Table 4, the productivity of $1 \mathrm{~F} 1 \mathrm{~W}$ is always the largest of all under different Manipulator cycle times. But considering the synchronization of the Manipulator improvement as discussed above, $1 \mathrm{~F} 1 \mathrm{~W}$ and $2 \mathrm{~F} 2 \mathrm{~W}$ will be ignored because of the flat slope and $2 \mathrm{~F} 3 \mathrm{~W}$ becomes the optimal combination to achieve the goal. For analyzing the slope of productivity per man-hour, Table 6 was created in the same manner in which Table 5 was created. In the Table 6, all of the values are negative except the values in the third column. Therefore considering the synchronization of the Manipulator improvement and the factor of profit and cost just mentioned above, $2 \mathrm{~F} 3 \mathrm{~W}$ is still the optimal choice in this case.

Table 5 Tree-Al gorithm : slope analysis

Relation be tween the increase of productivity and the number of labor PRODUCTIV ITY PER HOUR: VARIATION OF LA BOR

\begin{tabular}{|c|c|c|c|c|}
\cline { 2 - 5 } \multicolumn{1}{c|}{ MANIP. CY C.T IME } & $1 \mathrm{FW}-1 \mathrm{~F} 2 \mathrm{~W}$ & $1 \mathrm{~F} 2 \mathrm{~W}-2 \mathrm{~F} 2 \mathrm{~W}$ & $2 \mathrm{~F} 2 \mathrm{~W}-2 \mathrm{~F} 3 \mathrm{~W}$ & $2 \mathrm{~F} 3 \mathrm{~W}-3 \mathrm{~F} 4 \mathrm{~W}$ \\
\hline $18.6 \mathrm{~min}$ & 0.68 & 0.41 & 0.71 & 0.48 \\
\hline $153 \mathrm{~min}$ & 0.68 & 0.43 & 0.80 & 0.48 \\
\hline $13.88 \mathrm{~min}$ & 0.68 & 0.44 & 0.85 & 0.48 \\
\hline $11.7 \mathrm{~min}$ & 0.69 & 0.44 & 0.90 & 0.55 \\
\hline
\end{tabular}

Table 6 Tree-Algorithm : slope analysis

Relation between the increase of productivity per man-hour and the number of labor PRODUCTIV ITY PER MA N-HOUR: VARIATION OFLABOR

\begin{tabular}{|c|c|c|c|c|}
\cline { 2 - 5 } \multicolumn{1}{c|}{ MA NIP. CYC. TIME } & $1 \mathrm{~F} \mathrm{~W}-1 \mathrm{~F} 2 \mathrm{~W}$ & $1 \mathrm{~F} 2 \mathrm{~W}-2 \mathrm{~F} 2 \mathrm{~W}$ & $2 \mathrm{~F} 2 \mathrm{~W}-2 \mathrm{~F} 3 \mathrm{~W}$ & $2 \mathrm{~F} 3 \mathrm{~W}-3 \mathrm{~F} 4 \mathrm{~W}$ \\
\hline $18.6 \mathrm{~min}$ & -0.017 & -0.075 & 0.011 & -0.118 \\
\hline $15.3 \mathrm{~min}$ & -0.018 & -0.072 & 0.031 & -0.125 \\
\hline $13.88 \mathrm{~min}$ & -0.018 & -0.069 & 0.040 & -0.128 \\
\hline $11.7 \mathrm{~min}$ & -0.015 & -0.070 & 0.050 & -0.121 \\
\hline
\end{tabular}

Case of least idle time of pipe waiting manipulator to lift

The least the idle time of pipe waits Manipulator to lift, the more the percentage of the Manipulator is busy. A comparison of the percentage of waiting time in QUEUE 27 "CART/PIPE READY" is identified. When Manipulator cycle time equals 18.6 minutes, the best combination for achieving the goal is $3 F 4 \mathrm{~W}$. As Manipulator cycle time equals 15.3 minutes, the optimal combination switches to $2 \mathrm{~F} 3 \mathrm{~W}$. In the case of 13.88 and 11.7 minutes, the optimal combination changes back to $3 \mathrm{~F} 4 \mathrm{~W}$.

\subsection{Time-Deviation Analysis}

The study of this section was made by fixing the duration of all tasks initially and varying the duration of work task "FIT PIPE" by percentage under different Manipulator cycle times, then calculating the slope of productivity under different increasing or decreasing phases. The same was done for analyzing work task "WELD PIPE". Consequently, there are two objectives to be identified in the study: (1) The maximum productivity increase for the 
entire working crew, and (2) The maximum productivity increase per man-hour.

(1) The maximum productivity increase for the entire working crew (fitter and welder)

The results of productivity increase owing to the decrease of duration of tasks "FIT PIPE" is illustrated in Table 7. In Table 7, under the condition of different Manipulator cycle times, the modeler studied work task "FIT PIPE" with four different combinations (1F1W, $2 \mathrm{~F} 2 \mathrm{~W}, 2 \mathrm{~F} 3 \mathrm{~W}, 3 \mathrm{~F} 4 \mathrm{~W})$ and varied the task duration from increasing the task duration $40 \%$ to decreasing the task duration $60 \%$. Afterwards, in each increasing or decreasing phase, the modeler can obtain the different increase or decrease of productivity under these four combinations. In a certain decreasing phase of duration, the modeler would like to choose the combination whose slope is negative and has the maximum absolute value, thus the optimal combination for achieving the maximum increase of productivity can be obtained in the phase. Vice versa, in the increasing phase of duration, the combination whose slope is negative and has the minimum absolute value is preferred to avoid the excessive lost of productivity. The bold numbers shown in Table 7 identify the optimal combination under each increasing or decreasing phase. The study of work task "WELD PIPE" can be made in the same manner.

Table 7 Time Deviation : The productivity per hour slope analysis (WORK TASK: FIT PIPE)

(a) MANIPULATOR CYCLE TIME $=18.6 \mathrm{~min}$

\begin{tabular}{|c|c|c|c|c|c|c|c|c|}
\hline & & & & & & & & \\
\hline COMBI'N & $-60 \sim-50 \%$ & $-50 \sim-40 \%$ & $-40 \sim-30 \%$ & $-30 \sim-20 \%$ & $-20 \sim-10 \%$ & $-10 \sim 0 \%$ & $0 \sim 20 \%$ & $20 \sim 40 \%$ \\
\hline $1 \mathrm{~F} 1 \mathrm{~W}$ & 0 & 0 & -0.01 & 0 & -0.01 & 0 & -0.01 & $\mathbf{0}$ \\
\hline $2 \mathrm{~F} 2 \mathrm{~W}$ & -0.02 & -0.01 & -0.01 & -0.01 & -0.02 & -0.01 & -0.02 & -0.02 \\
\hline $2 \mathrm{~F} 3 \mathrm{~W}$ & -0.02 & -0.02 & -0.02 & -0.03 & -0.03 & -0.04 & -0.39 & -0.14 \\
\hline $3 F 4 W$ & -0.05 & -0.03 & -0.02 & -0.03 & -0.06 & -0.08 & -0.24 & -0.15 \\
\hline
\end{tabular}

(b) MANIPULATOR CYCLETIME $=15.3 \mathrm{~min}$

\begin{tabular}{|l|r|r|r|r|r|r|r|r|}
\hline COMBI & $-60 \sim-50 \%$ & $-50 \sim-40 \%$ & $-40 \sim-30 \%$ & $-30 \sim-20 \%$ & $-20 \sim-10 \%$ & $-10 \sim 0 \%$ & $0 \sim 20 \%$ & $20 \sim 40 \%$ \\
\hline 1F1W & 0 & -0.01 & 0 & -0.01 & 0 & 0 & $\mathbf{- 0 . 0 1}$ & $\mathbf{- 0 . 0 1}$ \\
\hline 2F2W & -0.01 & -0.01 & -0.01 & -0.01 & -0.01 & -0.02 & -0.02 & -0.02 \\
\hline 2F3W & -0.02 & -0.02 & -0.02 & -0.02 & -0.03 & -0.03 & -0.41 & -0.16 \\
\hline 3F4W & $-\mathbf{0 . 0 7}$ & $\mathbf{- 0 . 0 6}$ & $\mathbf{- 0 . 0 5}$ & $\mathbf{- 0 . 0 7}$ & -0.05 & $\mathbf{- 0 . 0 5}$ & -0.09 & -0.32 \\
\hline
\end{tabular}

(c) MANIPULATOR CYCLE TIME $=13.88 \mathrm{~min}$

\begin{tabular}{|l|r|r|r|r|r|r|r|r|}
\cline { 2 - 8 } COMBI & $-60 \sim-50 \%$ & $-50 \sim-40 \%$ & $-40 \sim-30 \%$ & $-30 \sim-20 \%$ & $-20 \sim-10 \%$ & $-10 \sim 0 \%$ & $0 \sim 20 \%$ & $20 \sim 40 \%$ \\
\hline 1F1W & 0 & 0 & -0.01 & 0 & -0.01 & 0 & -0.01 & -0.01 \\
\hline 2F2W & -0.02 & -0.01 & -0.01 & -0.02 & -0.01 & -0.01 & -0.02 & -0.03 \\
\hline 2F3W & -0.02 & -0.02 & -0.02 & -0.02 & -0.02 & -0.02 & -0.13 & -0.3 \\
\hline 3F4W & $\mathbf{- 0 . 0 6}$ & $\mathbf{- 0 . 0 7}$ & $\mathbf{- 0 . 0 6}$ & $\mathbf{- 0 . 0 5}$ & $\mathbf{- 0 . 0 4}$ & $\mathbf{- 0 . 0 3}$ & -0.06 & -0.44 \\
\hline
\end{tabular}

(d) MANIPULATOR CYCLE TIME $=11.7 \mathrm{~min}$

\begin{tabular}{l|r|r|r|r|r|r|r|r|} 
COMIBI & $-60 \sim-50 \%$ & $-50 \sim-40 \%$ & $-40 \sim-30 \%$ & $-30 \sim-20 \%$ & $-20 \sim-10 \%$ & $-10 \sim 0 \%$ & $0 \sim 20 \%$ & $20 \sim 40 \%$ \\
\hline 1F1W & -0.01 & 0 & 0 & -0.01 & 0 & -0.01 & 0 & -0.01 \\
\hline 2F2W & -0.01 & -0.02 & -0.01 & -0.01 & $-\mathbf{0 . 0 2}$ & -0.01 & -0.02 & -0.03 \\
\hline 2F3W & -0.03 & -0.02 & -0.02 & -0.03 & -0.02 & -0.02 & -0.44 & -0.2 \\
\hline 3F4W & $-\mathbf{0 . 0 5}$ & $-\mathbf{0 . 0 3}$ & $\mathbf{- 0 . 0 3}$ & -0.03 & -0.02 & $-\mathbf{0 . 0 5}$ & -0.08 & -0.44 \\
\hline
\end{tabular}

(2) The maximum productivity increase per man-hour

Under each combination ( $1 \mathrm{~F} 1 \mathrm{~W}, 2 \mathrm{~F} 2 \mathrm{~W}, 2 \mathrm{~F} 3 \mathrm{~W}, 3 \mathrm{~F} 4 \mathrm{~W})$, divide the values in Table 7 by the sum of working crew (i.e., fitter \& welder). For example, in Table 7 , the numbers in the first row were divided by two and the numbers in second row were divided by four. The results were shown in Table 8 . The bold numbers are the optimal combination under each increasing or decreasing phase. With the same manner discussed above, in a certain decreasing phase, the combination with the maximum absolute value is the optimal. Vice versa, in the increasing phase of duration, the combination with the minimum absolute is preferred. The 
optimal results in Table 8 have little change from the results obtained in Table 7. Depending on the different interests, the manager would have to trade-off according to the different results between these two methods in his decision-making process. In the same manner, the study of work task "WELD PIPE" is conducted.

Table 8 Time Deviation : The productivity per man-hour slope analysis (WORK TASK: FIT PIPE) (a) MANIPULATOR CYCLE TIME $=18.6 \mathrm{~min}$

\begin{tabular}{|c|c|c|c|c|c|c|c|c|}
\hline & & & & & & & & \\
\hline COMBI'N & $-60 \sim-50 \%$ & $-50 \sim-40 \%$ & $-40 \sim-30 \%$ & $-30 \sim-20 \%$ & $-20 \sim-10 \%$ & $-10 \sim 0 \%$ & $0 \sim 20 \%$ & $20 \sim 40 \%$ \\
\hline $1 \mathrm{~F} 1 \mathrm{~W}$ & 0 & 0 & -0.005 & 0 & -0.005 & 0 & -0.005 & 0 \\
\hline $2 \mathrm{~F}^{2}$ & & & & .0025 & -0.005 & -0.0025 & -0.005 & 0.005 \\
\hline & -0.004 & -0.004 & & -0. & -0.006 & -0.008 & -0.078 & -0.028 \\
\hline $3 F 4 W$ & 0.0071 & -0.0043 & -0.00280 & -0.00429 & -0.0080 & -0.0114 & -0.0343 & -0.02143 \\
\hline
\end{tabular}

(b) MANIPULATOR CYCLE TIME $=15.3 \mathrm{~min}$

\begin{tabular}{|l|r|r|r|r|r|r|r|r|}
\cline { 2 - 9 } \multicolumn{1}{c|}{ COMBI } & $-60 \sim-50 \%$ & $-50 \sim-40 \%$ & $-40 \sim-30 \%$ & $-30 \sim-20 \%$ & $-20 \sim-10 \%$ & $-10 \sim 0 \%$ & $0 \sim 20 \%$ & $20 \sim 40 \%$ \\
\hline 1F1W & 0 & -0.005 & 0 & -0.005 & 0 & 0 & -0.005 & -0.005 \\
\hline $2 \mathrm{~F} 2 \mathrm{~W}$ & -0.0025 & -0.0025 & -0.0025 & -0.0025 & -0.0025 & -0.005 & $-\mathbf{0 . 0 0 5}$ & $\mathbf{- 0 . 0 0 5}$ \\
\hline $2 \mathrm{~F} 3 \mathrm{~W}$ & -0.004 & -0.004 & -0.004 & -0.004 & -0.006 & -0.006 & -0.082 & -0.032 \\
\hline $3 \mathrm{~F} 4 \mathrm{~W}$ & $\mathbf{- 0 . 0 1}$ & $\mathbf{- 0 . 0 0 8}$ & $\mathbf{- 0 . 0 0 7}$ & -0.01 & $\mathbf{- 0 . 0 0 7 1}$ & $-\mathbf{0 . 0 0 7}$ & -0.01286 & -0.04571 \\
\hline
\end{tabular}

\begin{tabular}{|c|c|c|c|c|c|c|c|c|}
\hline \multicolumn{8}{|c|}{ LATOR CYCLE TIME $=13.88 \mathrm{n}$} & $20 \sim 40 \%$ \\
\hline $1 F 1 W$ & 0 & 0 & -0.005 & 0 & -0.005 & 0 & -0.005 & -0.005 \\
\hline $2 \mathrm{~F} 2 \mathrm{~W}$ & -0.005 & -0.0025 & -0.0025 & -0.005 & -0.0025 & -0.0025 & -0.005 & -0.0075 \\
\hline $2 \mathrm{~F} 3 \mathrm{~W}$ & -0.004 & -0.004 & -0.004 & -0.004 & -0.004 & -0.004 & -0.026 & -0.06 \\
\hline & 08 & & $.0 .008 t$ & .0071 & 0.005 & -0.0043 & -0.00857 & -0.0628 \\
\hline
\end{tabular}

(d) $M$ A NIPULATOR CYCLE TIME $=11.7 \mathrm{~min}$

\begin{tabular}{|c|c|c|c|c|c|c|c|c|}
\hline COMBI & $-60 \sim-50 \%$ & $-50 \sim-40 \%$ & $-40 \sim-30 \%$ & $-30 \sim-20 \%$ & $-20 \sim-10 \%$ & $-10 \sim 0 \%$ & $0 \sim 20 \%$ & $20 \sim 40 \%$ \\
\hline $1 \mathrm{~F} 1 \mathrm{~W}$ & -0.005 & 0 & 0 & -0.005 & 0 & -0.005 & 0 & -0.005 \\
\hline $2 \mathrm{~F} 2 \mathrm{II}$ & -0.0025 & -0.005 & -0.0025 & -0.0025 & -0.005 & -0.0025 & -0.005 & -0.0075 \\
\hline $2 \mathrm{~F} 3 \mathrm{WI}$ & -0.006 & -0.004 & -0.004 & -0.006 & -0.004 & -0.004 & -0.088 & -0.04 \\
\hline $3 F+W$ & -0.0071 & -0.00429 & -0.0043 & -0.00429 & -0.00280 & -0.0071 & -0.01143 & -0.06286 \\
\hline
\end{tabular}

\section{CONCLUSIONS}

This paper proves that Computer Simulation Method (CSM) is an appropriate method for the evaluation of construction productivity improvement by automation. It is known that productivity improvement of each work task by automation might cost money. The higher the degree of automation applied, the more cost increases. This study gives the decision-maker the information necessary to determine whether the effort is worthwhile by comaring investment of capital to improvement in productivity. That is, to analyze by how much productivity can be improved when the activity is improved by automation.

\section{REFERENCES}

1. Cheng, M.Y., "Simulation Analysis of Process Piping Construction", MS thesis, University of Texas, December 1989.

2. Fisher, Deborah J. "Piping Erection Constructability Issues in a Semi-Automated Environment." Ph.D. dissertation, University of Texas, May 1989.

3. Glass, Clinton C. "The Pipe Manipulator: A Complete Assessment of a New Idea in Construction Equipment Technology." MS thesis, University of Texas, Dec. 1984.

4. Halpin, Danicl W. "MicroCyclone uscr's Manual."; 1986, 1.0 version and 1988, V 2.0. 